\title{
AN OUTCOME DETERMINANT ANALYSIS OF NCAA RULES VIOLATIONS: AN APPLICATION OF MULTIVARIATE STATISTICS TO THE COMMITTEE ON INFRACTIONS' DECISIONS ON MAJOR CASES
}

\author{
Joshua R. Smith
}

\author{
A Thesis \\ Submitted to the Graduate College of Bowling Green \\ State University in partial fulfillment of \\ the requirements for the degree of

\section{MASTER OF EDUCATION}

August 2012

Committee:

Dr. Sungho Cho, Advisor

Dr. Ray Schneider

Dr. Amanda Paule-Koba 
(C) 2012

Joshua Smith All Rights Reserved 


\section{ABSTRACT}

Dr. Sungho Cho, Advisor

Since the National Collegiate Athletic Association (NCAA) began enforcing major rules infractions in 1953 , there has been concern over the causes and implications of the violations. Past research has explored the causes for many of the violations with a focus on the cartel theory of college athletics. Researchers have also studied the significance of self-imposing sanctions effecting the punishment imposed by the Committee on Infractions (COI). Though numerous studies have attempted to explain the phenomenon of NCAA major rules infractions, none have attempted to statistically calculate the consistency of sanctions enforced against every level of competition.

This study uses multivariate statistics to predict the outcome of NCAA rules violations. All major rules infraction cases since 1994 were examined with each charged violation and imposed sanction given a weight. An aggregate weighted score was determined for the overall violations and sanctions of 262 cases. A regression analysis shows the aggregate score of violations can significantly predict the severity of sanctions. Also, each case was analyzed to determine other key variables which could impact the Committee's decision. Among them included the division or level of competition, whether the institution was considered a repeat violator, whether the institution selfreported or self-discovered the violations and whether the institution imposed its own penalties. 
The significance of each independent variable was determined through a logistical regression analysis and descriptive statistical analysis. These multivariate models revealed the division of competition, repeat violator status and self-reporting do not have a significant impact on the severity of sanctions issued by the COI. An institution's decision to self-impose penalties does affect the overall sanctions imposed. The statistical analysis indicates being a repeat violator has no significant impact on the severity of sanctions. This finding along with the determination that self-reporting your own violations does not help to mitigate the severity of sanctions demonstrates a flaw in the Committee's decision-making.

The results from this study are important to industry insiders. Compliance officers will be able to utilize the information to formulate a plan when dealing with their own major infraction case. Also, with the NCAA creating a working group to explore the possibility of an enhanced enforcement and penalty structure, this study has the ability to shape the opinions of institutions when the comment period begins. 
To my son, Emery. I love you 7. 


\section{ACKNOWLEDGMENTS}

Dr. Sungho Cho for all his patience and expertise. Dr. Ray Schneider and Dr. Amanda Paule-Koba for their insight. Dr. Anderson for her guidance. Thank you to all my professors at Bowling Green who have made the years of education both rewarding and fun. 


\section{TABLE OF CONTENTS}

Page

INTRODUCTION ......................................................................................

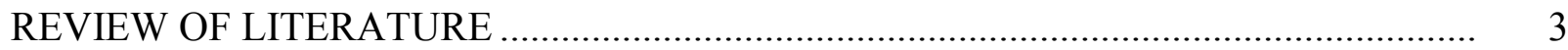

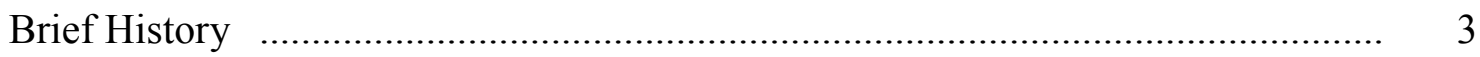

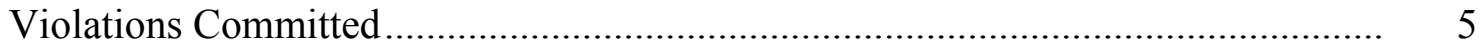

Case Studies $\quad$......................................................................................... 8

Factors Affecting Sanctions ................................................................. 10

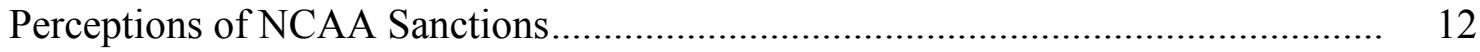

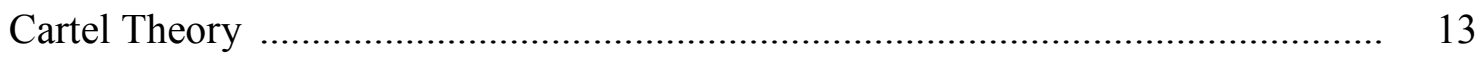

Competitive Balance ........................................................................... 17

Committee on Infractions ...................................................................... 21

Effectiveness of Sanctions ..................................................................... 23

RESEARCH QUESTIONS ........................................................................... 26

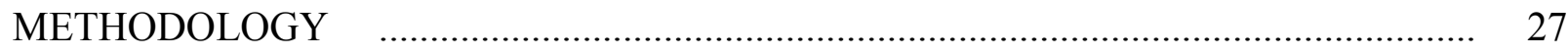

DATA ANALYSIS AND RESULTS................................................................... 38

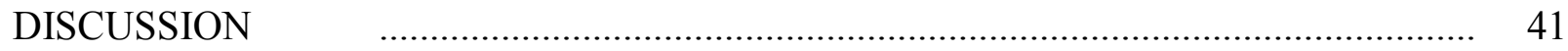

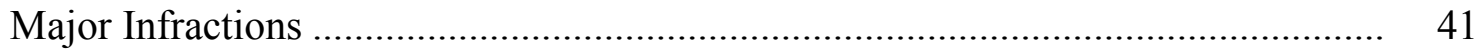

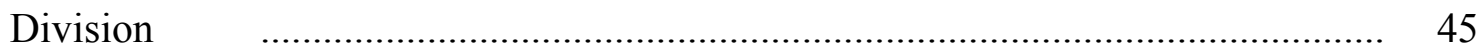

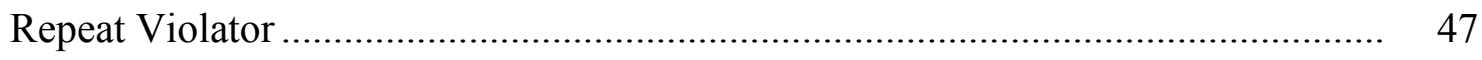

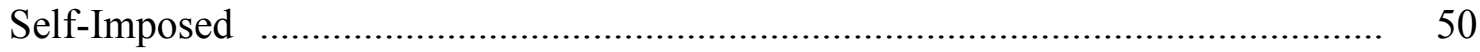

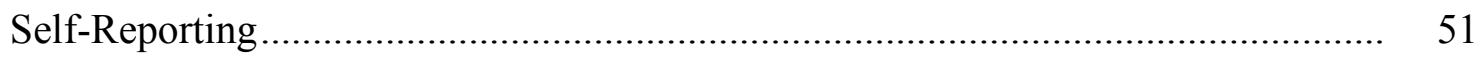

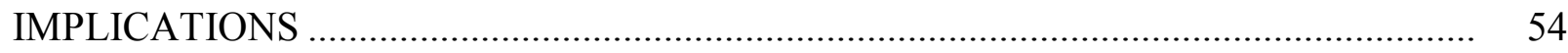




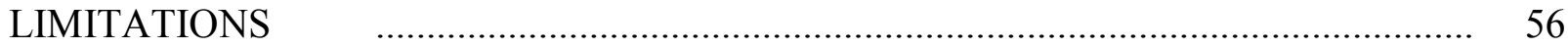

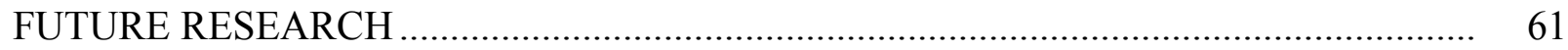

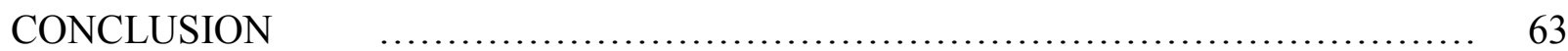

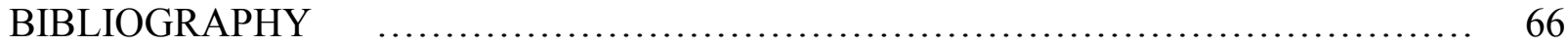

LIST OF FIGURES/TABLES

Figure/Table $\quad$ Page

$1 \quad$ Regression Analysis................................................................................. 39

2 Logistic Regression Analysis - Repeat Violator Status .................................... 39

$3 \quad$ Logistic Regression Analysis - Self-Imposed ............................................. 40

$4 \quad$ Logistic Regression Analysis - Self-Reporting .......................................... 40 


\section{INTRODUCTION}

It seems as if every week a new story emerges of an athletic department being embroiled in an NCAA investigation (Carter, 2012; Smith, 2012; Thamel, 2011). The media reports have become more salacious each time leading schools to become increasingly concerned about protecting their reputations. Researchers of NCAA rules violations have discovered that football team's on-the-field performance is affected negatively after being sanctioned (Clark \& Batista, 2009; Perry, 2002). This is due to the type of punishment that affects the ability of the program to recruit top talent. Institutions often times will also experience a decline in donations following sanctions for major rules violations (Grimes \& Chressanthis, 1994). Other research has discovered that self-imposing sanctions on a program that has committed major rules violations may have the chance of lessening the overall punishment imposed by the NCAA (Winfree \& McCluskey, 2008).

To determine a consistent punishment model of the Committee on Infractions it is necessary to understand all of the factors that can affect its decision-making. Previous research has uncovered relevant factors considered by the Committee on Infractions (Clifton, 2009; Dixon, Turner, Pastore \& Mahony, 2003; Humphreys \& Ruseski, 2006; Mahony, Fink \& Pastore, 1999; Winfree \& McCluskey, 2008). Among those factors include self-reporting violations and self-imposing initial sanctions; cooperating with the investigation; repeat violator status and overall history of compliance; foreseeability of the violation occurring; and employment status of those (coaches and staff) responsible for the violations.

The general public often times perceives various other factors as having significance on the sanctions issued. Earlier research focused on the increase in investigations and charges of 
major violations due to reputation and size of the athletic program; geography and proximate competitors; and volatility of a program's winning percentage (Eckard, 1998; Fleisher, Goff, Shughart \& Tollison, 1988; Fleisher, Goff \& Tollison, 1992; Fort \& Quirk, 1999). These areas have not been fully evaluated to determine whether they affect the type or severity of sanctions but many individuals in the general public and within the industry believe these factors lead to arbitrary and biased sanctioning decisions. A small sampling of research studying NCAA sanctioning decisions, however, has shown the NCAA makes consistent decisions based on case precedent (Clifton, 2009). The purpose of this study is to identify the key mitigating and aggravating factors that affect sanctions imposed on programs that have committed major rules violations and to determine whether the NCAA has remained consistent with its punishment. Providing a quantitative research could help clarify the nature of decisions and lead to greater transparency and confidence in the enforcement procedures. 


\section{REVIEW OF LITERATURE}

Previous analysis into NCAA sanctions for major rules violations has found that penalties against specific programs have typically been in accordance with past decisions (Clifton, 2009). Still, many individuals perceive a discrepancy in the severity of sanctions. Many fans, alumni, sport management professionals, radio pundits and state senators consider the penalties to be

arbitrary (Blumenthal, 2012; Staples, 2012). Those in the public may believe that the size, status or reputation of the institution plays a pivotal role in altering the appropriate sanctions and certain studies may support their belief (Baxter, Margavio \& Lambert, 1996; Fort \& Quirk, 1999; Humphreys \& Ruseski, 2006). Ultimately, the NCAA Committee on Infractions, before determining the ultimate punishment, considers various factors. Several potential mitigating factors which may be taken into account include: self-reporting; cooperation with the NCAA; self-sanctions; and disassociation with those responsible for the violations (firing the coach/staff responsible). Aggravating factors could also exist leading to enhanced sanctions, they include: repeat violator status, lack of cooperation with an investigation, and foreseeability of potential violations.

\section{Brief History}

The NCAA has been in existence since 1906 (Grimes \& Chressanthis, 1994) but did not provide the first enforcement mechanism for punishment of members for violations of its rules until 1946 (Depken \& Wilson, 2006). That year saw the creation of the "Principles of Conduct of Intercollegiate Athletics" and in 1948 it was incorporated into the NCAA constitution. It became known as the "Sanity Code" and regulated recruitment and retention of student-athletes (Depken \& Wilson, 2006). The Fact-Finding Committee investigated suspected violations 
followed by a Compliance Committee serving as the arbiter of those suspected violations. At this point "the only form of punishment available to the Compliance Committee was the termination of the violator's NCAA membership. [The] NCAA members deemed this punishment too draconian and stripped the Compliance Committee of its punitive role in 1951" (Depken \& Wilson, 2006, p. 828). Thus the Sanity Code was repealed without a single sanction having been imposed (Eckard, 1998).

In 1953, a range of sanctions became possible instead of mere termination as the NCAA members provided the Committee on Infractions (COI) with a continuum of powers. They included a limit on the number of scholarships, limit on television appearances, and limiting participation in postseason play (Depken \& Wilson, 2006). Thus, the NCAA has employed a credible enforcement mechanism since 1953. The NCAA penalty structure punishes more egregious violations with more severe penalties while minor offenses (including secondary) receive smaller punishments. The most severe punishment is considered the "death penalty" in which a program is prohibited from competing against other NCAA members. This has only occurred once and was temporary (Depken \& Wilson, 2006). The first penalties against major football programs were levied in 1953 against Notre Dame (public reprimand) and Arizona State (two year probation and one year bowl ban) (Eckard, 1998). During the 1960's and 1970's the NCAA's regulatory functions and enforcement procedures expanded considerably (Falla, 1981). Smith (2000) examined the history of the NCAA's role in regulating intercollegiate athletics. "Between 1840 and 1910 there was a movement from loose student control of athletics to faculty oversight, from faculty oversight to the creation of conferences, and, ultimately, to the development of a national entity for governance purposes (Smith, 2000, p. 12)." NCAA Bylaw 
2.1 states "it is the responsibility of each member institution to control its intercollegiate athletics program in compliance with the rules and regulations of the NCAA" (NCAA Manual, 2011, p. 3). The NCAA Manual provides for "broad and severe" penalties if the violation reflects general disregard for the governing rules (NCAA Manual, 19.01.5, 2011, p. 319).

A significant portion of literature has focused on the on-field performance of football programs before and after major violation penalties (Clark \& Batista, 2009; Perry, 2002). These studies examined the extent of major violations and the sanctions brought about by them and how they subsequently affected the performance of the programs responsible. These articles do not, however, directly examine whether the NCAA has remained consistent with its sanctions of major rules violations. Rather, they attempt to determine what effects occur to the program following the issuance of those sanctions.

\section{Violations Committed}

Various researchers have stated for years that NCAA violations are on the rise (Jordan, Greenwell, Geist, Pastore, \& Mahony, 2004; Mahony, 1999). Other literature has analyzed the number of NCAA recruiting violations committed and defined who is most likely to commit such violations (Baxter, Margavio \& Lambert, 1996; Clark \& Batista, 2009). Baxter et al (1996) show that certain types of NCAA Division I schools are more likely to violate NCAA rules thereby receiving sanctions. Baxter used a pooled cross section of penalties to reach a conclusion regarding multiple hypotheses. First, successful athletic schools are more likely to experience major sanctions than less successful schools. Second, schools with higher academic standards and are more selective of undergraduate admissions are less likely to be penalized for violations. Third, schools with a higher number of proximate competitors are less likely to be 
penalized by the NCAA than are schools with a small number of proximate competitors. Advanced research will evaluate whether successful athletic schools are experiencing more major sanctions at a higher rate than less successful schools because they are more prone to committing those violations or more attention is focused on them simply because of their past success. Still, the more appropriate aspect of research is whether those successful programs who have committed major rules violations are being punished more severely than less successful programs who have committed similar major rules violations.

The finding on proximate competitors affecting the chance of being penalized was conducted using data pre-1994 when the NCAA eliminated mandatory penalties for recruiting violations reducing the likelihood of proximate competitors monitoring each other (Humphreys \& Ruseski, 2006; Zimbalist, 1999). While Baxter et al (1996) took into account all major violations between $1952-1990$, it should be noted that nearly $66 \%$ of all major violations are recruiting violations (Clark \& Batista, 2009), which could significantly alter their findings regarding penalties dependent on number of proximate competitors.

Mahony, Fink \& Pastore (1999) studied many of the relevant issues surrounding NCAA violations and sanctions when they examined NCAA violations and penalties from 1952-1997. This research continues much of what Mahony and colleagues did in this study as it looked to answer several important questions. The article explored both men's and women's intercollegiate sports in all divisions to find if an increase was occurring in both the number of violations and severity of punishment. This study looked back at data from the earliest available point starting in 1952 up until 1997. During this period it was discovered that $81 \%$ of violations committed by men's programs were at Division 1 institutions. Mahony found this statistic to be 
relatively stable throughout the decades. This could be due to closer scrutiny from the NCAA and interested third parties or from having more on the line financially leading to more actual violations.

In the 1950 's it was found that $100 \%$ of the men's programs that violated NCAA rules were revenue sports (Mahony et al, 1999). That number drastically changed in the 1990's as only $58 \%$ were committed by revenue sports. The total over the time period amounted to $79 \%$. Of most interest is the data for penalties for the men's programs. They found that while the public reprimands $(21 \%)$ have stayed relatively stable over the decades, the number of years on probation has increased significantly from 1.20 in the 1950 's to 2.56 in the 1990 's. Even in the 1980 's the average number of years on probation was only 1.39 indicating a tougher stance on violations occurring primarily in the 1990's. In contrast, the number of years for post-season bans and television bans has decreased over the years. The NCAA has instead increased scholarship reductions and recruiting limitations. Continued research will determine whether these trends in severity of sanctions have continued over the past decade and look closer into the factors affecting those penalties.

Scholarship reductions, coaches being penalized and forfeiting of contests are the sanctions that have seen the largest increases. This shows that the NCAA has altered its penalty structure to be more in tune with what it believes is fairer and will deter future violations. As for women's programs it was found that nearly $82 \%$ of violations occurred at Division 1 level with $35 \%$ of those committed by revenue sports. The percentage of women's programs violating academic rules (48\%) and eligibility (67\%) was found to be greater than it was for men's (34\% and 58\%). The average length of probation for women's sports in the 1990's was 2.67 years up 
from 0.95 years in the 1980's. The post-season bans in women's sports are low at .67 years (Mahony et al, 1999).

\section{Case Studies}

One case study of significance was conducted by Clifton (2009), which analyzed the major recruiting rule violations affecting the Indiana University men's basketball program. He compared their sanctions against similar situations at other universities in an attempt to determine whether the punishment incurred by Indiana University was fair in comparison to what others schools incurred. Clifton considered factors such as the history of the program (no past major infractions for the IU men's basketball program), the decimation of the program, and the foreseeability of the recruiting violations as significant factors both for increased penalties and against it.

The violations occurred when the new head basketball coach, Kelvin Sampson, and his assistants made over 100 impermissible phone calls to potential recruits in violation of NCAA rules. These were the same violations that he had been accused of at his previous job leading the NCAA to charge IU with a failure to monitor violation, as the compliance department should have done a more thorough job of preventing and detecting. The long history of running a clean program was a factor that worked in Indiana's favor when the Committee on Infractions leveled its punishment, as was the decimation of the program caused by the violations. This was evident by the fact that the program only retained two of its student-athletes following the accusations. A number of student-athletes transferred or were dismissed from the team as were the coaches involved in the violations. 
Clifton then compared the sanctions (three years probation, self-imposed scholarship reduction and recruiting limitations) to other schools that went through similar violations. The study looked at BYU, Oklahoma, Middle Tennessee State and Chicago State each of which incurred sanctions due to recruiting violations. The BYU case was similar due to the fact that the compliance department was made aware of specific potential for violations (foreseeability) and still failed to properly monitor the situation. They were struck with three years probation, public reprimand, scholarship reductions and recruiting limitations. After referencing each of the similar cases, Clifton determined that the Indiana sanctions were fair based on both the mitigating and aggravating factors (Clifton, 2009). This case study compares NCAA precedent on major recruiting rule violations between schools but does not explore other types of violations on a larger scale.

Ferraro (2003) examined the NCAA sanctions imposed on the University of Minnesota men's basketball team. This case study went in depth on the rampant violations that occurred at Minnesota during the tenure of men's basketball head coach Clem Haskins. In it the author outlined the misconduct and gives the self-imposed and NCAA imposed sanctions from those violations. The study then suggests potential preventative measures to try and assure this type of situation doesn't happen again. This case study consisted of violations of NCAA bylaws governing academic fraud, extra benefits, academic eligibility, unethical conduct and lack of institutional control. The university self-imposed penalties ranging from a one year post-season ban, reduction in scholarships, limitation on recruiting, and a return to the NCAA of monies earned from participating in the NCAA tournament. They also reorganized the compliance office to provide greater oversight from a non-athletic source. Even with all of these self- 
imposed sanctions the NCAA Committee on Infractions deemed them insufficient and also hit the university with "show cause" procedures on the head coach and others involved plus vacation of team records and individual records and awards for student-athletes involved in the academic fraud. "These penalties may perhaps be the most effective because they eliminate the achievements earned through the improper benefits afforded through the academic fraud committed by the players and facilitated by the institution" (Ferraro, 2003, p. 20). This article examined a single case study involving various bylaw violations and the penalties associated. It suggests a potential for further sanctions that could have a significant impact of deterring future violations but does not examine the overall trend of NCAA penalties. Ferraro and Clifton provide a baseline for this research by evaluating individual programs and their violations in comparison to similar situations.

\section{Factors Affecting Sanctions}

Self-punishment for rules violations has been shown to affect NCAA sanctions (Winfree \& McCluskey, 2008). In 1976, the University of Minnesota became the first instance of a university self-imposing punishment for rule violations. Today, schools self-impose a punishment nearly $69 \%$ of the time with the NCAA accepting without additional major penalties $6 \%$ of the time (Winfree \& McCluskey, 2008). Winfree \& McCluskey's study argued that violators should punish themselves in order to affect the level and type of punishment thereby minimizing lost revenue. They argue that the NCAA does take into account self-punishment because the association wants to be perceived as fair. Still, it cannot be assumed that after nearly 35 years since the first occurrence of an institution self-imposing sanctions on its own program, the NCAA continues to place significance on self-punishment. A program runs the risk of being 
too punitive with self-imposed punishment and thus may wish to allow the NCAA to set the punishment as it sees fit based on precedent.

Their study included data from 192 observations of NCAA Division I schools' major rules infractions. It included all sports between 1987 and 2006 and looked at six main punishment categories. Those categories were split into discrete punishment variables (television ban, post-season ban, and probation) and indicator variables (reduction in financial aid/scholarships, recruiting limitations, and employee restriction such as "show cause"). Using an ordered multinomial probit model (OMPM), the results indicated some self-imposed punishments can sometimes lead to decreased penalties in other punishment categories. This study, however, does not take into account other potential factors that the Committee on Infractions may consider. It fails to address the potential for greater cooperation from those selfimposing institutions or history of compliance. Future studies examining the consistency of NCAA sanctions should consider more variables that could influence the punishment beyond mere self-imposed penalties.

According to the results, self-imposing a reduction in total scholarships to studentathletes can decrease the expected probation given by the NCAA. On the other hand, selfimposing a restriction on employees showed little effect on the amount of punishment handed out by the NCAA. The final results from the study showed that, recruiting and eligibility violations significantly increased the years of the television ban punishment. NCAA membership, ethical conduct, eligibility, financial aid, and administrative regulation violations significantly increase the years of post-season ban, while enforcement violations decrease postseason bans. Violations of principles of conduct, institutional control, and recruiting 
significantly increase years of probation, but conduct and employment of athletics personnel seems to decrease the years of probation. "Previous violations clearly have a significant impact on the final punishment" according to the authors (Winfree \& McCluskey, 2008, p. 203). A school with a previous infraction (not sure if that has to be of the same type of violation or any) increases the probability of a one-year television ban by $1.47 \%$ while self-imposed probation decreases the probability of a one-year television ban by $10.88 \%$.

\section{Perceptions of NCAA Sanctions}

In determining whether the sanctions imposed on institutions by the NCAA are fair, it is important to gauge the perceptions of athletic department insiders including coaches, compliance officers, and student-athletes (Barnes \& Marley, 2009; Dixon, Turner, Pastore \& Mahony, 2003; Sack, 1988). Dixon et al (2003) conducted a qualitative study on rule violations in intercollegiate athletics. Their investigation examined the perceived areas of injustice among men's and women's basketball coaches at the Division I level. It used an organizational justice theory of individuals from different institutions to highlight findings of perceptions regarding NCAA rules and sanctions. The participants included four men's and two women's NCAA Division I basketball recruiting coordinators from both major and mid-major conferences. The most relevant aspect of the study came from the perceptions of NCAA enforcement and fairness of their sanctions. The coaches did not feel that the NCAA treated schools differently because of their size or categorization as major or mid-major but they questioned the fairness of the penalties being dispensed for recruiting violations. The majority of participants indicated their belief that the NCAA should impose stiffer penalties for recruiting violations. This study helps understand the perceptions of those involved in intercollegiate athletics regarding the fairness of 
NCAA sanctions. Since this study was conducted in 2003, the NCAA has informed their institutions of a desire to increase sanctions on all major violations (Wieberg, 2008).

Many early studies focused on the effects of contribution levels on rules violations (Grimes \& Chressanthis, 1994). Grimes \& Chressanthis (1994) found that NCAA sanctions for rules violations may slightly reduce annual contributions to an athletic department. The study expounded upon past articles that focused on the reason for athletic donations by using the data to examine the effect of NCAA sanctions. They studied Mississippi State University to find variables that play a role in alumni donations. Evidence was found to prove a negative effect of NCAA sanctions on alumni contributions to academics. The sanctions may negatively influence alumni who are sensitive to the institution's athletic success while they "have the potential to penalize an entire academic institution, not just its intercollegiate athletics program" (Grimes \& Chressanthis, 1994, p. 37)

\section{Cartel Theory}

Under the cartel theory of NCAA sanctions, researchers have evaluated the effect of enforcement of NCAA rules on various programs (Eckard, 1998; Fleisher, Goff, Shughart \& Tollison, 1988; Fleisher, Goff \& Tollison, 1992; Fort \& Quirk, 1999). Fleisher, Goff, Shughart \& Tollison (1988) promoted the notion that the NCAA detects rule violations according to the volatility of a program's winning percentage. Their findings also suggest that the enforcement of the NCAA rules has a redistributive effect benefitting consistent winners at the expense of upand-coming schools. This early study of the NCAA as a cartel attempted to develop and test a theory of NCAA enforcement activity. It hypothesized who wins and who loses from such enforcement activities. Competitors will observe on the field performance to tell whether a 
program is cheating. Where there is a volatile change in winning percentage it may be an indicator that the program is violating the NCAA rules leading to possible investigations.

The NCAA cartel is enforced through the annual NCAA manual which imposes restrictions on schools, coaches, student-athletes and alumni. At the time this article was written the NCAA relied on competitors to inform them of potential violations, schools were not expected to self-police themselves. In doing so, competitors could directly monitor other schools by looking for cancelled checks, cosigned loans, travel accounts or letters to prove illegal inducements to recruits. This was obviously a costly procedure and time consuming so schools rarely took to direct monitoring. Instead, they would monitor outputs rather than inputs in the form of on-the-field performance. This theory only makes sense with the notion that there is a link between recruiting and winning.

The hypothesis of Fleisher et al (1988) is that a higher variability of winning percentage would raise the probability of investigation and probation. They also expected to see a correlation between older schools and violations as the more alumni a school has and the more demand for better football leads to more opportunities to make illegal inducements for recruits. Also, winning teams that switch conferences face a higher likelihood of being sanctioned by the NCAA, so will institutions surrounded by more high schools as it increases the cost of monitoring and leads to more cheating and sanctions. The authors found that "NCAA enforcement favors consistently successful teams, and does not bother itself with teams that never win. Consistent winners are no more likely to be convicted of violations than are consistent losers" (Fleisher, Goff, Shughart \& Tollison, 1988, p. 445). This was determined 
from the data that showed teams appearing most often in the top 20 are not the most heavily sanctioned, instead those teams with more variable records suffer the most sanctions.

The study also found that the mean winning percentage over a five year span before the violation up to the first year the football program was placed on probation led to an increase in winning percentage. There was a $26 \%$ increase in winning percentage for teams on probation beginning five years before whereas non-probation teams decreased in winning percentage (though very little, $0.0015 \%$ ). From the start of the probation term until four years out, the data shows a decrease of $8 \%$ in mean winning percentage for those teams. This would account for one more loss per season in those years following being placed on probation. The study mentions the results for repeat offenders, suggesting the NCAA watches them more closely but it does not account for how much more severe penalties will be based on repeat offenses (other than stating the death penalty for SMU as a repeat offender). Consistent winners will turn in the up and coming teams leading to probation and causing many to believe the NCAA conspires to keep the traditional football powers at the top.

Evidence has been reported that NCAA enforcement efforts are most often times directed towards programs showing recent improvements in competition (Fleisher, Goff \& Tollison, 1992). Fleisher et al (1992) found higher variability in a team's winning percentage leads to a greater probability of the NCAA taking enforcement action against that institution. The researchers did not however, test for the effects on competitive balance as does future researchers such as Eckard. Eckard (1998) presented one of the first studies to examine how NCAA enforcement affects competitive balance in major college football conferences. The study continued the research of the enforcement of the NCAA football as a cartel, using NCAA 
violations and penalties to understand the system. Eckard suggests when traditionally weak football programs sign top prospects this could be a red flag, and the NCAA should look into potential recruiting violations. His findings show a decline in winning percentages post 1952 for schools (private) with higher academic standards. His evidence supported the notion that cartel enforcement could reduce playing field competitive balance as recognized in conference standings and national rankings.

Programs that have a consistently successful football team have less to gain from committing rules violations (Fort \& Quirk, 1999). Fort \& Quirk (1999) suggested that, Teams with low winning percentages, large unused stadium capacity, and large potential TV and attendance markets stand to gain the most from violating NCAA recruiting violations... while athletic programs with successful football teams that have high winning percentages and make frequent bowl appearances, wealthy donors, and play in lucrative TV and attendance markets do not stand to gain much from violating the regulations and are less likely to cheat (p. 18)

Humphreys \& Ruseski (2006) suggest that for the NCAA to function properly its members must self-police and impose sufficiently severe penalties on member institutions in order to deter cheating. The study investigated various factors that could explain the probability of an institution being caught violating NCAA recruiting violations and being punished for those violations.

The empirical evidence in Humphreys \& Ruseski’s study suggests that pre-1993; variations in factors such as lagged winning percentage, coaches' experience, and unused stadium capacity could be used to predict the teams that were placed on probation. The 
predictability of these factors did not continue during the post-1993 data set. Starting in 1994 the NCAA eliminated mandatory penalties for recruiting violations, allowing institutions to investigate and monitor themselves. It appears from the data that this policy change had a significant effect on the predictability of recruiting violations based on identified factors. From the data set 1978-1993, an "increase in wins of one in the previous year from a 5-6 record to a 65 record increased the probability of a team being on probation in the current year by about $2 \%$. An increase in wins of five in the previous year from a 5-6 record to a 10-1 record increased the probability of a team being on probation in the current year by about $10 \%$, other things equal" (Humphreys \& Ruseski, 2006, p. 159). The results also showed that a "10\% increase in unsold tickets at a team's stadium in a season increase[d] the probability that the team [would] be on probation by 6.8\%" (Humphreys \& Ruseski, 2006, p. 159). These numbers significantly decreased in the 1994-2005 time period largely due to the change in recruiting policy.

Humphreys \& Ruseski recognized that unobservable factors such as reputation and commitment to academics could affect the probability that an institution is punished for violating NCAA recruiting violations. Their research looked at factors that may affect NCAA enforcement but did not study the factors that could alter the severity of sanctions. It also looked at only one type of violation to one sport to find the chances an institution was placed on probation. Further studies would expand the data set to examine more sports and types of major violations and sanctions.

\section{Competitive Balance}

The next approach from researchers was to analyze infractions to study the theory that football championships are influenced by NCAA violations. Clark \& Batista (2009) extended 
Humphreys \& Ruseski’s research by conducting a trend analysis of Division 1 (FBS) infractions. The analysis examined the frequency and distribution of NCAA major infractions from 1970 to 2007. The Knight Commission (2001) noted that over half of NCAA Division 1 programs have been sanctioned by the NCAA or placed on probation at some point since 1953. This study inquired whether highly competitive BCS affiliated conference schools would be more likely to commit recruiting infractions than Non-BCS institutions. They broke the analysis up according to conference and geographic regions while also looking for trends in recruiting violations since 1987.

Clark \& Batista used a trend analysis by univariate analysis of variance to measure the means of major and secondary violations. The secondary violations were compiled since 2002 when the NCAA began recording level I and level II secondary infractions. The NCAA does not mention the universities involved with these violations making the data less significant than major violations. They found that secondary violations have increased over $362 \%$ between 2002 and 2007 with recruiting violations increasing from 216 to 863 from 2002 to 2003.

The data collected on major violations indicated that schools affiliated with one of the six BCS conferences committed $77 \%$ of major violations committed by Division I FBS schools between 1970 and 2007. This confirmed to the researchers that the level of competition influences major violations in NCAA Division 1 (FBS) athletics. Since only one non-BCS conference member has won a national championship since 1970, the researchers concluded that a "relationship exists between the frequency of major infractions and the opportunity to compete for a national championship" (Clark \& Batista, 2009, p. 13). The Big 12 conference was found 
to rank highest in terms of mean violations per year and mean violations per team per year followed by Pac 10, Big Ten, SEC, ACC, and Big East (Clark \& Batista, 2009).

The SEC committed the most major recruiting violations within the BCS conferences followed by the Big Ten, Big 12, Pac 10, ACC, and Big East. According to the study, whenever co-national champions have been named in football, major recruiting violations increased in the conferences whose teams won, with the exception of the Pac 10 in the years of 1990-1993 (Clark \& Batista, 2009). This indicates that disputed national championships may be a cause for major recruiting violations. Still, other teams in the conference rather than the co-national champion commit many of those violations. Thus, when a BCS conference member wins a national championship it puts pressure on other conference members to remain competitive, and leads to more major recruiting violations.

The elimination of strength of computer rankings reducing the effect of quality wins in 2005 affected the average number of NCAA major recruiting violations. In 2002, 2003, and 2004 the average was 7 per year, which exceeded the mean of 4.9 infractions per year. After 2004 the average number of major recruiting violations decreased to 3.69 in 2005-2007. Of course, non-BCS conference schools commit fewer major recruiting violations. When analyzing the data according to geographic region, the research found that universities in the south accounted for $35 \%$ of major recruiting violations while universities in the Midwest committed $28 \%$ of all FBS major recruiting violations. The other geographic regions rounded out with the southwest (16\%), west (15\%), mid-Atlantic (6\%) and New England (0\%). These numbers correspond with the number of championships by region with the south winning $55 \%$ of FBS championships, Midwest 25\%, west 20\%, southwest 15\%, and mid-Atlantic and New England 
$0 \%$. Southern universities typically commit more major recruiting violations and win more championships in football than the rest of the nation.

Depken \& Wilson (2006) extended the research of Fleisher, Goff, \& Tollison (1992); Eckard (1998); and Depken \& Wilson (2004) when it studied the effects of NCAA enforcement on the competitive balance in Division 1 (FBS) college football. They found that while a greater level of enforcement improves competitive balance, greater severity of punishment tends to reduce competitive balance. The net result, however, is NCAA enforcement activity improves the competitive environment of college football. This research studies only major Division 1 FBS football conferences to determine NCAA enforcement on competitive balance. It does not evaluate all divisions and all sports in an effort to understand the trends in NCAA punishment or detect factors that may lead to more or less severe penalties.

Their findings showed that the average number of investigations per football conference was 1.40 for conferences where at least one investigation took place and the average number of probations pending was 1.08 . They concluded that the NCAA uses past "bad" behavior of conference members to determine where to direct their enforcement efforts. The average length of probation across all data sets was found to be approximately one year. Within conferences with at least one probation pending the average length increased to 1.69 years. Interestingly, the researchers found that the average length of probation has increased over the years with nine instances of five-year probations occurring between 1996 and 2003. This could prove a harsher penalty structure from the NCAA or simply more egregious acts of cheating from member institutions coupled with the possibility of repeat violations accumulating. This research will 
determine whether the probation lengths have increased based on aggravating factors or if it appears decisions by the Committee on Infractions are being made arbitrarily.

The findings of the Depken \& Wilson study indicate that the severity of punishment handed out to a football program in terms of probation years is associated with a decrease in competitive balance meaning teams perform worse after being put on probation. Each investigation of a football program improves competitive balance by approximately $6 \%$, "whereas a one-year increase in the average length of pending probations reduces the competitive balance measure by approximately 1.7\%" (Depken \& Wilson, 2006, p. 837). The authors opine that actual punishment in the form of probations have more effect and thus are more appropriate measures of punishment than are investigations. Of course, probation does not hurt the program instantaneously but rather the results show a steady effect over a 4-5 year time frame. The results indicate NCAA sanctions do influence member behavior and the improved competitive balance provides for greater fan interest, as more teams become bowl eligible. The type and severity of sanctions should change over time until the NCAA finds an appropriate punishment that sufficiently deters future violations.

\section{Committee on Infractions}

Another important aspect of understanding the consistency of the sanctions is an evaluation of the Committee on Infractions. Marsh (2009) wrote an article calling for greater representation on the Committee on Infractions. The NCAA's lack of subpoena power greatly limits their ability to fully enforce its rules and regulations. Marsh set out to recommend some changes to the Committee on Infractions. His first recommendation was to increase the number of public members on the committee who had no affiliation with institutions or conferences. He 
would suggest increasing the number of public members from 2 to 4 (three are currently allowed in the NCAA bylaws). This would bring a greater sense of objectivity to the process and would alter the appearance that the members are all aligned with the NCAA against the individuals appearing before them. Marsh understands, however, that having former coaches and administrators on the committee remains important as their experience provides greater insight into the proposed penalties "with a realistic assessment of whether proposed penalties relating to such things as scholarships, official visits, and recruiting restrictions were warranted and fair" (Marsh, 2009, p. 709). These individuals build credibility within the process.

Marsh notes that Committee opinions never present dissenting opinions. While eight members vote on potential penalties, the final opinion does not present the dissenters rather all dissenters join the majority. Most cases are not in great dispute as all the facts are typically agreed to after the university has self-reported the violation. The majority of allegations that tend to create discussion are violations involving lack of institutional control, failure to monitor or a charge of unethical conduct against a coach or staff member. Thus, Marsh calls for recognizing dissenting opinions due to their ability to strengthen the process and the NCAA rules over time. He is afraid that without dissenting opinions the public will continue to perceive the committee as a rubber stamp for the enforcement staff and walking in tandem with the NCAA without fair judgment of the situation.

The Committee on Infractions presents an interesting factor in this study. The Committee is made up of 10 members, eight of which have voting power. These members are primarily made up of former NCAA coaches and administrators (athletic directors or faculty athletic representatives) with typically two public members (former judges). With no dissenting 
opinions ever written to give the public a feel for how the vote formulated or why it was determined the way that it was, we are left without a valuable piece of information that would be helpful to this thesis. In many cases involving lack of institutional control or failure to monitor the vote may have come out 5-3 in favor or against it making the decision closer and more complicated then the public was led to believe.

\section{Effectiveness of Sanctions}

Most recently, Weston (2011) analyzed the effectiveness of NCAA sanctions on the offending programs, actual wrongdoers, and student-athletes most impacted. She sought to understand whether the sanctions imposed by the Committee on Infractions was placing the correct amount of punishment on those most directly involved or if innocent student-athletes were feeling the brunt of the penalties. In her introduction, Weston summarizes the recent sanctions levied against the University of Southern California (USC) and their basketball and football programs. The football program was hit with serious sanctions in large part due to the egregious nature of the extra benefit violations but also because the program was deemed a repeat violator.

Weston begins by describing the NCAA enforcement process, which includes the right to appeal the COI decision. Her complaint is that NCAA sanctions' reach is both "overly limited and overly broad." This is due to the fact that NCAA,

Sanction powers extend only to member institutions, not to individual coaches, players, agents, boosters, or involved individuals who are not direct members of the NCAA. The reach of the sanctions has ripple effects that impair uninvolved programs and innocent 
student-athletes, both financially and with respect to playing opportunities (Weston, 2011, p. 565).

The sanctions may also impact other conference members as the offending school may generate less revenue providing for less of a distribution to other members.

Weston's analysis of the USC sanctions unearths the philosophy of the Committee on Infractions regarding the institution's responsibility to monitor its student-athletes. In its report, the COI stated that heightened scrutiny is required for star student-athletes who would obviously have more potential for big payoffs as a professional and thus more potential for third party involvement and opportunity to receive extra benefits. This mentality of the COI is critical in understanding how they view the compliance efforts of different institutions. Larger, and more successful, programs which recruit elite talent for their high profile programs will be expected to monitor their actions more closely than they would with lesser known or bench players. At what point is a program complicit in failing to monitor its star student-athletes?

Weston makes some suggestion of ways to better align the penalties with the violations without placing so much of the burden on innocent parties. Her proposals do not first come with an examination of the standard penalties that are associated with misconduct. It would be helpful to align the proposals with a detailed account of the standard sanctions. Numerous other studies have examined the impact of sanctions on the programs and institutions (Grimes \& Chressanthis, 1994; Sack, 1988). Her first suggestion is to hold the head coaches financially accountable for program violations. By tying the coaches' compensation and bonuses to a violation-free program, the institution is more likely able to assure the coach is attempting to abide by the NCAA rules rather than circumvent them. NCAA Operating Bylaw 11.1.2.1 (2011) states, 
It shall be the responsibility of an institution's head coach to promote an atmosphere for compliance within the program supervised by the coach and to monitor the activities regarding compliance of all assistant coaches and other administrators involved with the program who report directly or indirectly to the coach (p. 49).

The second suggestion is for institutions to give back money or to be hit with further financial penalties. The implication is that if the NCAA would attack the institutions that violate rules in a monetary fashion then they would be less inclined to violate those rules. Bylaw 19.5.2.2(f) already imposes a potential financial penalty against institutions that violate the rules. She suggests the idea of a luxury tax against violators that takes into account the total athletic department revenue before coming up with a percentage as a penalty. The money could then be distributed to other NCAA institutions that have run clean departments for a length of time. The third suggestion is open transfer rules for current student-athletes in programs under major sanctions. Lastly, she suggests that professional sport franchises refrain from hiring sanctioned personnel and states should pass legislation aiming to bar agents from practicing within the state if the agent induces a student-athlete to violate NCAA rules.

This research addresses whether NCAA sanctions for major rules violations are consistent across institutions. Combining relevant factors as determined from past studies and other recognizable mitigating and aggravating factors deciphered from recent cases of violations, a determination can be made regarding the significance those factors have on the ultimate punishment received. 


\section{RESEARCH QUESTIONS}

Have the sanctions imposed by the Committee on Infractions for major rules violations remained consistent? The consistency of decisions would provide the NCAA with greater credibility and lessen the negativity that surrounds it. A determination of whether the decisions on major rules infractions is consistent may help to answer or support the critics who claim the NCAA is unfair. The most drastic step taken by the NCAA to deter and punish violators was the introduction of the repeat violator bylaw. This enforcement bylaw was enacted to severely punish those institutions that continue to violate the rules. This study examines whether the repeat violator rule has been consistently enforced. Does an institution's status as a repeat violator have a significant aggravating impact on the overall sanctions imposed? Other aspects within the control of the offending institution include the decision to self-impose penalties and the proper monitoring procedures leading to greater oversight and self-discovering of violations. Does self-reporting or self-imposing sanctions mitigate the punishment levied against offenders? Finally, what trends in major rules violations and sanctions have occurred since $1994 ?$ Specifically, what changes has the Committee on Infractions made to its punishment structure and have these changes created an unfair or biased model? 


\section{METHODOLOGY}

This study examined factors that may potentially affect the sanctions imposed by the Committee on Infractions upon institutions charged with committing major rules violations. The factors, and the severity attributed to each, were determined based off of four separate sources: previous literature, major rules infraction cases, NCAA bylaws, and a panel of industry experts. These sources provide direct and indirect evidence into the severity of each variable and offer the most insight into the significance of each factor. The previous literature on the subject showed how certain violations are weighed more heavily against the violator. The literature has also implied that there are different levels of severity of sanctions (Ferraro, 2003; Clark \& Batista, 2009; Humphreys \& Ruseski, 2006). Within many of the major infraction cases the Committee has provided evidence of its perception on the severity of violations and sanctions. Academic fraud, for example, has been framed as one of the most serious violations on numerous occasions by the COI (Baylor, 1995; Georgia Southern, 1995; Minnesota, 2000). The NCAA manual is a standard source to gather information regarding the severity of violations and sanctions. It provides separate articles covering institutional control and ethical conduct expected from each of its member institutions. It also details the authority granted to the COI in issuing punishment (Bylaw, Article 19).

Finally, a small panel of industry experts was consulted as a source to categorize each violation and sanction. These industry experts consisted of four compliance officers across three states and three levels of intercollegiate athletics. Two of the experts are from mid-major schools in the Midwest, one was from an FCS institution in the south, and the final expert was from a BCS school in the southwest. These industry experts provided perspective into the 
NCAA enforcement procedures along with their personal opinions on the severity of specific violations and sanctions. Their insight, along with the other three sources, was used to smooth the hundreds of potential violations into five increasingly severe categories.

The first category was considered the least severe and garnered the lowest score (1) with each succeeding category increasing in severity (2-5). The formula for the severity of sanctions differed from the violations as the research focused on eight distinct forms of sanctions. Each sanction was given a score ranging from 1 to 4 with one being the least severe and four being the most severe. Three of the sanctions were then broken apart based on the length of the sanction. Television bans were deemed the most serious sanction and were broken into two parts. A oneyear television ban received a score of 3 while a two year television ban received a score of 4 . There were no television bans beyond two years between 1994 and present. Postseason bans were given staggered scores with one year worth two (2) points, two years worth (3) and three years worth (4) points. There were no postseason bans beyond three years in the sample of cases. The final sanction separated based on number of years was the length of probation. Probation for an institution for 1-2 years was worth one (1) point while probation of 3 years and beyond was awarded two (2) points. Probation was determined less severe than television and postseason bans as they have become standard forms of punishment for violators with diminishing significance. There is little chance a member institution will be punished more severely for a secondary violation because of being on probation and any other major violation would automatically fall within the repeat violator status under the bylaws if it occurs within five years. Therefore, probation was given a lower score than the preceding types of violations. 
The other sanctions deemed the least severe, for this research, include vacating records and show cause orders. Ferraro (2003) suggested vacating records might be of more significance to programs as it wipes out individual and team performances from the record books. In reality, and based on industry expert opinions, vacating records has little impact on the member institution as it is impossible for the NCAA to force fans, staff and student-athletes to forget about the games that were actually played. Being forced to take down a championship banner may take away some of the luster from a recruiting visit but it won't hurt nearly as much as a ban or loss of scholarships. In a similar manner a show cause order has little impact on the institution. A show cause order places a restriction on any NCAA institution from hiring the penalized individual without showing due cause. This penalty has less effect on the institution than it does on the individual being prevented from working for an NCAA institution.

The next level of sanctions was recruiting limitations. The NCAA has the power to limit the amount of recruiting an institution can be involved in for both major and secondary violations. Typical restrictions include limiting the total number of off-campus contacts and evaluations, preventing coaches from recruiting off-campus, reducing the number of official visits allowed, preventing coaching staffs from calling recruits and complete prohibition from recruiting a prospective student-athlete. Recruiting restrictions are presumptive penalties for major recruiting violations and, since recruiting is the lifeblood of any program, may have an impact on the ability of a school to compete. Sanctions limiting recruiting activities received a score of two (2) regardless of the exact type of limitation and the length of such limitations. This determination was made due to the fact that these limitations are presumptive for major recruiting violations and the various lengths would have been difficult to properly categorize. A 
typical case could consist of two weeks limitation on off-campus recruiting, counting an impermissible contact as one of the seven allowed, and no contact with the specific prospective student-athlete for one month. There is typically a variation in length of limitations of no more than a couple weeks. While a further categorization of restrictions on recruiting would be more accurate, in the consideration of the complexity of the data set, researchers have not subcategorized the sanction.

Perhaps the hardest sanction to categorize is the reduction in financial aid. The COI has placed more focus on punishing violators with a loss of scholarships while some institutions have chosen to self-impose these sanctions to avoid other sanctions of perceived greater severity. The research has split reduction in scholarships into those amounting to less than $10 \%$ of total grantin-aids available for the program(s) and those amounting to $10 \%$ or greater. The $10 \%$ amount was found to be the average reduction imposed on programs. The researcher recognizes the impact on varying sports programs where a loss of one scholarship can have drastically different effects depending on the size of the roster.

The first factor worth considering is the type of violation(s) which have been charged against the institution. The types of violations have been smoothed into five categories based on the NCAA bylaws, previous literature (Mahony, Fink \& Pastore, 1999), major infraction cases and suggestions from a panel of industry experts. Using the NCAA manual as a guide the violations are smoothed into these five categories: recruiting, playing and practice seasons, financial aid, amateurism, and unethical conduct.

The majority of violations can be grouped together according to the referenced bylaw mentioned in the infractions report. The first category of violations, considered least serious in 
nature, is recruiting violations. Most recruiting bylaw violations are deemed secondary in nature but can rise to the level of major when multiple violations occur. Recruiting violations are listed under NCAA Bylaw 13 with the majority of them being smoothed together into Category 1 . The primary exception is with Bylaw 13.2 involving offers and inducements to prospective studentathletes and their relatives or friends. This subsection involves more egregious violations as determined by reference to the NCAA manual and the opinion of experts. Bylaw 19.02.2.2 states a major violation is any violation not regarded as secondary, "specifically including those that provide an extensive recruiting or competitive advantage" (NCAA Manual 19.02.2.2). Many recruiting violations are inadvertent and only give rise to major when an excessive amount occurs over an extended period of time (University of Cincinnati, 2011; New Hampshire, 2009; BYU, Hawaii, 2009). When this occurs the NCAA enforcement is more likely to impose additional charges against the institution such as failure to monitor and lack of institutional control.

Playing and practice seasons, found in Bylaw 17, are Category 2. Playing and practice season violations include coaches requiring their student-athletes to practice beyond the 20 hour per week limit during the season (17.1.6.1) or 8 hours per week outside the playing season (17.1.6.2). Other examples of violations under this bylaw include: failure to provide the appropriate number of days off per week (17.1.6.4 and 17.1.6.5), voluntary athletically related activities (17.02.13), conditioning activities (17.1.6.2.4), out of season athletically related activities (17.9.6), and hour limitation record (17.1.6.3.4). Category 2 also includes violations of coaching staff limitations as found in bylaw 11.7.1.1.1. An examination of major infraction cases found that violations of 11.7 (limitations on the number and duties of coaches) were 
closely connected to instances of playing and practice season violations. The determination to include 11.7 violations in Category 2 was further warranted following an inquiry into the opinions of expert analysis who confirmed the belief that coaching staff limitations violations are often times inadvertent and provide a minimal competitive advantage. They occur inadvertently when the head coach believes a graduate assistant or undergraduate assistant is allowed to perform a wider range of functions than permitted by NCAA rules. Category 2 is viewed as more serious in nature than Category 1 (recruiting) but still relatively innocuous compared to the proceeding categories.

Category 3 includes violations of Bylaw 15, financial aid. The NCAA regards impermissible financial aid violations as a mid level infraction yet this section deserves careful consideration as to the severity of the violation. Financial aid infractions often times occur as a mere oversight by the institutional department and are quickly rectified. Consistent financial aid violations lead to failure to monitor charges and potential lack of institutional control and can be considered extra benefits to the student-athlete (MacMurray College, 2005; University of Nebraska, 2012). Violations of the financial aid bylaw are typically referenced as: inconsistent financial aid package, impermissible financial aid (Buffalo State College, 2010; Georgetown, 2009; Temple, 2007), impermissible staff involvement in financial aid, improper reduction in financial aid, excessive financial aid (Ball State, 2007; Bethune-Cookman, 1995; Miami, 1995), improper out of state fee waiver (Washington State, 1994), and improper use of financial aid (Slippery Rock, 1996). A handful of cases have involved the improper use of financial aid to purchase items other than course related books (University of San Francisco, 2010). In the 2010 
University of San Francisco infractions case, the COI noted that all future "bookstore type" violations will include a reduction in financial aid.

At the heart of numerous major infraction cases is the violation of NCAA rules pertaining to amateurism and eligibility. The amateurism violations (Bylaw 12) will also include violations of Bylaw 14 (eligibility) and Bylaw 16 (awards, benefits). This category will also contain recruiting inducements as described in Bylaw 13.2. The NCAA Manual specifically addresses recruiting inducements as a "significant impermissible benefit" which should be considered in the same regards as an extra benefit to a current student-athlete (NCAA Manual, 2011, p. 319). Potentially the most significant violation regards the impermissible receipt of extra benefits. Extra benefits can come from numerous sources but primarily from either coaches/staff or from boosters. The payment of extra benefits to student-athletes from institutional employees is more troublesome and uniformly leads to charges of unethical conduct. Extra benefits from boosters, however, are less likely to lead to unethical conduct charges against institutional staff members but may be the basis for a failure to monitor or lack of institutional control violation. Other types of violations listed under Category 4, amateurism, include: ineligible participation, preferential treatment, impermissible compensation, charges of failure to enforce and violations involving student-athlete employment such as payment for work not performed. These charges have been smoothed together into one category based on an examination of major infraction cases.

The fifth and most serious category is listed under unethical conduct. The majority of violations smoothed together under unethical conduct violations are attributed to Bylaw 10 but other violations are listed under Bylaw 2 (principles for conduct), Bylaw 19 (enforcement) and Bylaw 32 (enforcement policies). These unethical conduct violations include: failure to monitor, 
lack of institutional control, failure to notify, failure to act with exemplary conduct, failure to promote an atmosphere for compliance and academic fraud. These categories were decided upon according to NCAA rules, cases (Boise State, 2011; Florida State, 2009), previous literature and through suggestions from a panel of industry experts. The violations will be weighted with a combined aggregate score.

One of the factors considered is whether the institution self-imposed its own penalties. This factor was determined through an examination of previous literature (Winfree \& McCluskey, 2008), review of cases (Oklahoma, 2011; Texas A\&M, 1994), and through the suggestion of a panel of industry experts. It is important to consider self-imposed penalties as a factor that may affect NCAA sanctions due to the fact that self-imposing penalties has become common practice for institutions involved in major rules violations. Institutions that choose not to impose even the minimum penalties may face harsher punishment from the Committee on Infractions.

A second related factor is whether or not the institution self-reported or self-discovered the violations. This factor was suggested by a panel of industry experts and each infractions case mentions whether the institution self-reported its own violations. Self-reporting or discovering violations shows the $\mathrm{COI}$ that an institution was proactive in monitoring its compliance efforts and attempting to put an end to any violations that may have already occurred. While a lack of self-reporting may lead to a greater likelihood of enhanced violations (i.e. failure to monitor or lack of institutional control) it may also directly lead to greater sanctions imposed by the Committee. 
The analysis considered the number of past major violations and the status of an institution as a repeat violator. NCAA Bylaw 19.01.5 states, "previous violations of NCAA legislation shall be a contributing factor in determining the degree of penalty" (NCAA Manual, 2011, p. 319). The repeat violator bylaw, 19.5.2.1, subjects institutions to enhanced penalties when they have committed further major violations within five years from the last major violation. Still, previous cases have indicated the Committee's unwillingness, in certain situations, to impose enhanced penalties on repeat violators (i.e. Alabama, 2009; Florida International, 2008; Memphis, 2009). An examination of this factor will determine whether the COI has remained consistent when considering enhanced penalties under bylaw 19.5.2.1.

The emphasis of the research is on trying to determine whether the level of play impacts the final punishment levied against institutions for major rules violations. For this reason, the division of the institution will be a factor. This factor was included based on suggestions from a panel of industry experts and previous literature (Baxter, Margavio \& Lambert, 1996; Fleisher, Goff, Shughart \& Tollison, 1988). The NCAA is made up of three distinct division, I, II and III. Division I, however, is further divided based on football alliances. This research separated institutions within six categories: Division I - FBS-BCS; Division I - FBS-Non AQ (automatic qualifier); Division I - FCS; Division I - no football; Division II; and Division III. The distinction between Division I schools is necessary to determine whether the COI is biased towards or against larger, more prestigious athletic institutions.

Finally, the level of sanctions was weighted with an aggregate score determined. The NCAA manual lists the penalties for major rule violations (NCAA Bylaw 19.5.2): public reprimand, probation up to 5 years, suspension of staff members, reduction in financial aid, 
reduction in expense paid recruiting visits, limits on recruiting activities, prohibition from outside competition, vacation of record, financial penalty, and show cause. The repeat violator status bylaw (NCAA Bylaw 19.5.2.1) allows for enhanced major violation penalties plus prohibition from some or all outside competition, elimination of all initial grant-in-aids and all recruiting activities, requirement that all institutional staff members serving on Board of Directors and other cabinets resign their positions, and relinquish of voting privilege.

Based on previous literature (Winfree \& McCluskey, 2008; Mahony, Fink \& Pastore, 1999) and suggestions from a panel of industry experts, this study included eight (8) separate sanctions. It also divided certain sanctions and weighted them according to the length and number of total sanctions (i.e. number of years on probation or postseason ban, number of total grant-in-aids reduced). The most severe sanctions consist of television bans, postseason bans and other bans on outside competition. Less severe penalties include probation, reduction in financial aid, and recruiting limitations. Finally, less severe penalties against the institution include show cause and vacation of records.

The data set was drawn from 262 cases of major rule infractions as listed on the NCAA website (ncaa.org/lsdbi). The data begins in 1994 and continues to the present. The year 1994 was chosen because that is when the NCAA eliminated mandatory penalties for recruiting violations thereby reducing the likelihood of competitors monitoring each other and instead creating a system of self-monitoring (Winfree \& McCluskey, 2008). Each major rules infraction case was analyzed and an Excel spreadsheet created to enter data for the factors previously mentioned. Two statistical models were used to analyze the data set. First, a multiple regression analysis was done with the level of sanctions as the dependent variable. The multiple regression 
analysis was used to predict the probability of sanctions based on the numerous factors. Second, a logistical regression analysis was used to predict the probability of sanctions in which the selfimposed, self-reported and repeat violator factors were considered binary dependent variables. Each case was analyzed for these factors and coded with either a yes (1) or no (0) response. The logistical regression model is necessary to account for these binary variables. 


\section{DATA ANALYSIS AND RESULTS}

The results of this study indicate that the aggregate score of violations significantly predicts the severity of sanctions $\left(\mathrm{R}^{2}=.364 ; \mathrm{p}<.05\right)$. Table 1 shows a regression analysis where the dependent variable is the severity of the sanctions imposed by the NCAA and independent variables are the aggregated score of violations and different division/BCS status $(\mathrm{N}=262)$. The aggregated score of violations combined the weighted value attributed to each violation (1-5) committed by the institution. The aggregated score of sanctions added the weighted score of each sanction imposed against the institution (1-4) to determine a total value. These numbers were inserted into the regression analysis to determine a standardized coefficient. The findings suggest past major rules infractions cases (262 since 1994) have remained consistent dependent on the aggregate score of violations and sanctions $(\mathrm{B}=.601)$.

In contrast, different divisions or size of athletic programs extrapolated from the BCS status was not significant $(\mathrm{p}>.05)$. The result indicates that the severity of NCAA sanctions has been consistent regardless of BCS related status. Multivariate statistics show that, using the regression analysis with the division as the constant variable, the different levels of competition (FBS-BCS; FBS-Non-AQ; FCS; Division I-no football; Division II; Division III) do not significantly alter the outcome of major rules infraction cases.

Table 2 shows whether the severity of sanctions predicts the repeat violator status. This logistic regression analysis shows that the repeat violator status may not be explained by the severity of sanction $(\mathrm{p}>.05)$. The aggregate sanctions was used as a constant variable with the repeat violator status as a binary independent variable. It is inferred that repeat violation would be a significant factor in NCAA sanctions. Therefore, the variable alone is not dispositive in the 
NCAA disciplinary proceedings. Another logistic regression tests whether the self-imposed penalties would affect the severity of sanctions (Table 3). Here, the severity of sanctions is influenced by the self-imposed penalties $(\mathrm{p}<.05)$. Hence, it is possible to extrapolate that selfimposed sanctions would be a significant variable coming into play in the NCAA disciplines.

Table 4 presents how self-reporting or self-discovering would affect the severity of sanctions. The logistic regression result shows that the dependent variable is not significantly affected by the independent variable $(\mathrm{p}>.05)$. It shows that self-report alone is not a dispositive factor in the process.

Table 1 Regression Analysis

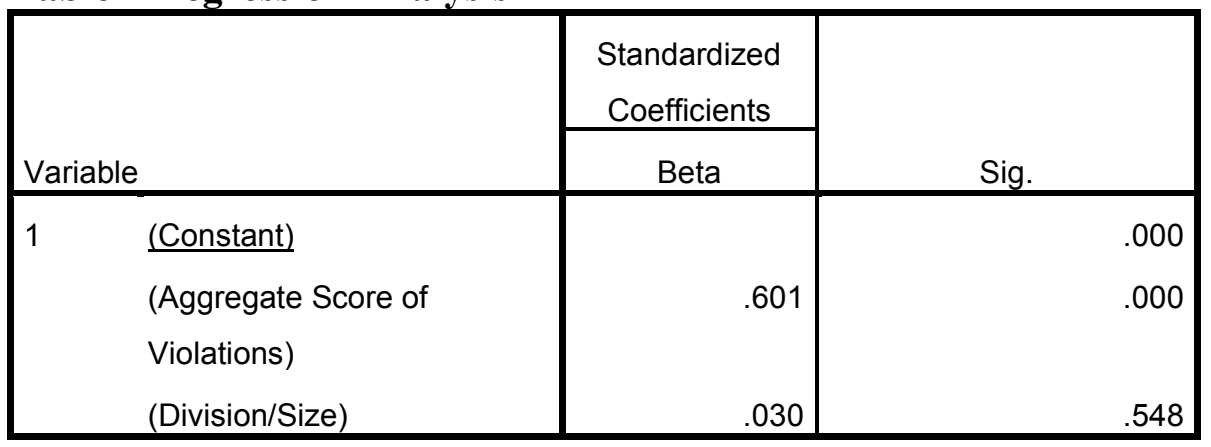

Note: $\mathrm{N}=262$

Table 2 Logistic Regression Analysis - Repeat Violator Status

\begin{tabular}{|c|c|c|c|c|c|}
\hline \multicolumn{6}{|c|}{ Variables in the Equation } \\
\hline & & $\mathrm{B}$ & Wald & df & Sig. \\
\hline \multirow[t]{2}{*}{ Step $1^{a}$} & Aggregate Sanctions & -.097 & .991 & 1 & .320 \\
\hline & Constant & -.845 & 1.484 & 1 & .223 \\
\hline
\end{tabular}

a. Variable(s) entered on step 1: Aggregate Sanctions. 
Table 3 Logistic Regression Analysis - Self-Imposed

Variables in the Equation

\begin{tabular}{|c|c|c|c|c|c|}
\hline & & $\mathrm{B}$ & Wald & $\mathrm{df}$ & Sig. \\
\hline \multirow[t]{2}{*}{ Step $1^{a}$} & Aggregate Sanctions & .208 & 4.765 & 1 & .029 \\
\hline & Constant & 1.409 & 7.466 & 1 & .006 \\
\hline
\end{tabular}

a. Variable(s) entered on step 1: Aggregate Sanctions.

Table 4 Logistic Regression Analysis - Self-Reporting

Variables in the Equation

\begin{tabular}{|ll|r|r|r|r|}
\hline & \multicolumn{1}{|c|}{ B } & \multicolumn{1}{|c|}{ Wald } & \multicolumn{1}{c|}{ df } & \multicolumn{1}{|c|}{ Sig. } \\
\hline Step $1^{\mathrm{a}}$ & Aggregate Sanctions & -.074 & 2.765 & 1 & .096 \\
& Constant & 1.169 & 13.918 & 1 & .000 \\
\hline
\end{tabular}

a. Variable(s) entered on step 1: Aggregate Sanctions. 


\section{DISCUSSION}

Findings and implications of this study were analyzed categorically. First, the overall findings of all major infractions that have occurred from 1994 through the beginning of 2012 will be presented and discussed. Next, an examination of the effect division (level of competition) or size of the athletic program has on the severity of sanctions. Then, the significance of being classified as a repeat violator will be discussed. This variable examines whether the Committee on Infractions utilizes its' power to impose enhanced penalties on institutions who have committed a second major infraction within five years of a previous major infraction. The following segment will explore the effect self-imposing has on the severity of sanctions. Finally, this section will conclude with a look at the impact self-reporting or selfdiscovering violations has on the overall level of punishment.

\section{Major Infractions}

NCAA Bylaw 19.02.2.2 states "all violations other than secondary violations are major violation" (NCAA, 2011, p. 320). This specifically includes "those (violations) that provide an extensive recruiting or competitive advantage" (p. 320). While secondary violations are typically self-reported by institutions (Clark \& Batista, 2009), major violations are sometimes discovered and reported by a third party. The NCAA has recorded major violations into its Legislative Services Database (LSDBi) beginning with cases in 1953. There are currently 683 major infractions cases listed on LSDBi. Some 259, or 38\%, of those cases include reduction in scholarships as a sanction while 213 (31\%) include recruiting restrictions. A show cause order was found in $186(27 \%)$ cases and $103(15 \%)$ include vacation of records. 
Major infractions in all sports (male and female) and all divisions were collected from the LSDBi. The data includes 262 major violation cases that occurred from 1994 through the beginning of 2012 (February 1, 2012). The year 1994 was chosen as the cut off as it marks the year the NCAA altered its monitoring policy in a way that promoted self monitoring (Winfree \& McCluskey, 2008). Prior to this period member institutions essentially policed each other. Schools located in close proximity to other member institutions were less likely to be penalized by the NCAA (Baxter et al, 1996; Humphreys \& Ruseski, 2006; Zimbalist, 1999). Thus, the change in monitoring policy became a seminal point in NCAA compliance as it altered the monitoring paradigm. Beginning the collection of data at this date range reduces the effect of including data from a far different era of monitoring and enforcement.

The enforcement bylaw of Article 19 creates a standard for member institutions to follow and a penalty structure for the Committee on Infractions to utilize. The Committee has the authority to issue sanctions ranging across a broad spectrum of punishment. NCAA bylaw 19.5.2 provides eleven separate penalties that the Committee may impose on an institution. Some of the most common penalties include public reprimand and censure, probation, reduction in financial aid, recruiting restrictions, vacation of records and show cause order. The Committee also has the authority to prohibit television appearances, postseason bans and issue financial penalties. Nearly $32 \%$ of the major infraction cases since 1994 have included a postseason ban while only 5\% have imposed a television ban. The last imposed television ban occurred in 2010 and only five television bans have been imposed since 1997.

The COI has shied away from issuing longer postseason bans over recent years instead focusing on extended probationary periods. During this time just two institutions have received 
postseason bans beyond two years. Texas Christian University (TCU) in 2005 and Texas Southern (1996) were prohibited from postseason for three years. At TCU the track and field program was involved in multiple recruiting violations and charges of academic fraud plus numerous unethical conduct charges and failure to monitor. The COI considered the nature and scope of the violations along with the egregiousness and competitive advantage gained from the multitude of violations before deciding to restrict the program from competition for three consecutive postseasons. The only previous precedent from this era of compliance came in 1996 when Texas Southern was hit with multiple amateurism charges, academic fraud and lack of institutional control in several sports including football, track and field, baseball, men's tennis and men's golf. Of particular interest to the Committee was the excessive number of studentathletes allowed to participate while ineligible. The severity of sanctions brought against Texas Southern was among the strictest ever brought against a program not considered to be a repeat violator.

The last FBS school to face a television ban was Baylor University in 1995. Baylor was found to have committed multiple violations of academic fraud as well as improper awarding of financial aid to ineligible student-athletes, among other violations. The Committee brought additional charges against the university including three counts of unethical conduct and lack of institutional control. An aggregate score of violations totaled 68 with the sanctions consisting of a one year television ban, one year postseason ban, recruiting limitations, a show cause order and greater than $10 \%$ reduction in financial aid for the sport involved. Later the same year Georgia Southern encountered a similar situation dealing with violations of academic fraud, ineligible practice, unethical conduct charges plus lack of institutional control. The Committee, once 
again, imposed a one year television ban where the aggregate score of violations and sanctions were similar to Baylor.

It seemed that the Committee had decided to come down hard on institutions guilty of academic fraud. Many of the most severe sanctions have been imposed against a member institution found to have committed academic fraud. This keeps in line with the NCAA's philosophy of protecting the academic integrity of its members and student-athletes. Out of the 27 cases that included academic fraud, 18 involved either a postseason ban and/or a television ban. The television ban was a natural deterrent as it has the dual effect of harming a school's ability to recruit and reduces revenue generation (an institution banned from television appearances is also banned from receiving revenue from any conference television deals during the proscribed period).

Only 13 institutions have been penalized with a television ban since 1994 (Texas A\&M, 1994; Washington, 1994; Coastal Carolina, 1994; Mississippi, 1994; Bethune-Cookman, 1995; Baylor, 1995; Georgia Southern, 1995; Maine, 1996; Stephen F. Austin, 2002; Nicholls State, 2005; Central Oklahoma, 2008; Lane College, 2008; Lincoln University, 2010). Then, in July of 1996 New Mexico State came before the Committee on charges of academic fraud, ineligible participation, unethical conduct and lack of institutional control, among other charges. New Mexico State's aggregate score of violations was close to that of Baylor nearly one year earlier and they received an aggregate score of violations directly in line with the previous cases. They did not however receive a television ban beginning a change in philosophy away from television bans. Instead the Committee chose to impose a postseason ban and three years probation to go along with a show cause, recruiting limitations, reduction in scholarships and vacation of 
records. In 2010, the Committee imposed significant sanctions on the University of Southern California including two years postseason ban for the football program. In the Committee's report they indicated a desire to impose a television ban but decided against it. While the Committee has shied away from television bans they have begun imposing a higher number of financial penalties against violators. These financial penalties have not been calculated for this study but will be important for future research to explore.

The regression analysis indicates that the aggregate score of sanctions is dependent on the aggregate score of violations. The results (Tables 1-3) show that the aggregate score of violations charged against an institution significantly predict the severity of the sanctions imposed $\left(\mathrm{R}^{2}=.364 ; \mathrm{p}<.05\right)$. Thus, without taking into consideration the mitigating and aggravating variables to follow, we can safely predict the aggregate sanctions of future major infractions based on the violations committed. This shows that the NCAA is not arbitrary in its punishment but instead remains consistent from case to case. While the Committee may decide to impose one type of equally severe penalty instead of another, the aggregate score of sanctions has remained fair; dependent upon the aggregate score of violations it also demonstrates that the rationale of the coding scheme implemented in this study would likely be coherent.

\section{Division}

Analysis of major violations data provides an understanding of how schools are being punished based upon their level of competition or division. While previous research has concluded that the "level of competition influences major violations in Division 1 (FBS) athletics," (Clark \& Batista, 2009) it is not apparent that the level of competition has any significant affect on the overall punishment imposed ( $p>.05)$. Since 1994, nearly $34 \%$ of all 
major violations have been committed by BCS affiliated schools. The overall percentage of major violations committed at the Division I level during this time amounts to $76 \%$ with Division II committing $17 \%$ and Division III accountable for 7\%. The regression analysis (Table 3) indicates no significant variation based on different divisions or level of play.

The average aggregate score of violations for Division I institutions (Average ASV = 24.02) is higher than Division II (Average ASV = 22.55) and III (Average ASV=12.05). Past research has examined the possibility of bias in charges brought against institutions competing at a lower level of competition (Baxter, Margavio \& Lambert, 1996; Fort \& Quirk, 1999; Humphreys \& Ruseski, 2006). While these studies have shown potential differences in charges, the Committee on Infractions has not unfairly imposed harsher sanctions on different divisions of intercollegiate athletics. This study has found that based on the 202 unique cases brought against Division I member institutions, the severity of sanctions has been fairly imposed in comparison to the 42 Division II cases and 18 Division III cases. As the number of individual violations and severity of charges have increased, so have the sanctions. An argument may be made that the COI has been harsher on smaller schools at lower levels of competition regarding the allocation of television bans. As previously stated, the last FBS school to be handed a television ban was Baylor in 1995. Since that time four FCS programs, two Division II and one Division III schools have been punished with a television ban (Nicholls State in 2005 was self-imposed). Of course, a ban from appearing on television is likely to have a more severe immediate impact on an FBS program than would most lower level counterparts. With this knowledge the COI may have felt hitting a lower level institution with a television ban would have less impact than other potential sanctions such as scholarship reductions or even recruiting limitations. 
This study found that across Division I there remains no significant difference in the severity of sanctions. Institutions were classified into four separate Division I categories. There are two classifications of FBS schools, BCS automatic qualifiers making up the six major conferences (Big Ten, Pac-12, Big 12, SEC, ACC and Big East) and non-automatic qualifiers (non-AQ). Non-AQ schools are from the mid-major conferences including the Mid-American Conference (MAC), Western Athletic Conference (WAC), Mountain West, Sun Belt and Conference USA. The third tier of Division I is Football Championship Subdivision (FCS). This level of competition competes in a football playoff rather than bowl games. There are currently 14 conferences comprising FCS. The final categorization of Division I are those institutions which do not field a football program but compete at the Division I level in all other sports. This includes schools such as Marquette University and Georgetown.

The findings indicate BCS-affiliated institutions average a lower aggregate score of violations $(\mathrm{ASV}=23.24)$ than FBS non-automatic qualifier institutions (FBS Non AQ; ASV= 26.27) and Football Championship Subdivision (FCS) institutions (ASV = 24.51). Though the BCS automatic qualifier schools make up just $27 \%$ of the Division I membership, they accounted for over $44 \%$ of all major infractions cases at the DI level. While greater research has been conducted explaining the disparity in the frequency of violations across Division I, these findings suggest there the severity of sanctions across all levels of competition are consistent dependent upon the severity of violations committed.

\section{Repeat Violator}

The NCAA created the repeat violator rule in order to deter and seriously punish programs that continually violate the rules. NCAA Bylaw 19.5.2.1 states that an institution is 
labeled a repeat violator if the "Committee on Infractions finds a major violation has occurred within five years of the starting date of a major penalty." Thus, at least one major violation must occur "within five years after the starting date of the penalties in the previous case."

Nearly $16 \%$ of the cases in the data set involved a repeat violator. A handful of other institutions avoided being labeled a repeat violator as the most recent major violation occurred prior to the penalties taking effect from the previous case. Among the 41 repeat violators, on average, the case causing them to be labeled a repeat violator was the fifth major violation case including the University of Arkansas who, in 2007, got hit with being a double repeat violator for having appeared before the Committee on Infractions for the third time in 10 years. Certain institutions seem to appear before the Committee on a regular basis. The University of Oklahoma has appeared before the Committee eight separate times while Arizona State University and Southern Methodist University have appeared before the Committee nine times each, though often times for different sports and different rule violations.

The typical punishment for repeat violators has been probation for three years with only 15 of the 41 institutions receiving a postseason ban. Four cases involved postseason bans beyond one season. Twice the Committee imposed a prohibition on outside competition against the repeat violator. In 2005, the COI used its discretion under 19.5.2.1.2 to limit the men's basketball team to conference games. In 1998 the COI accepted the University of Louisville's self-imposed penalty cancelling a preseason women's volleyball competition in Japan. A show cause order was imposed 26 times while recruiting limitations applied to 25 cases and the vacation of records 18 times. The reduction in financial aid was applied to 33 of the 41 repeat violator cases with just 11 of those imposing greater than $10 \%$ reductions on the program. In 
comparison, $61 \%$ of cases not involving repeat violators that were sanctioned with a reduction in scholarships saw less than $10 \%$ reduction. The percentage of non-repeat violator cases receiving greater than $10 \%$ reduction in scholarships was exactly the same as with the repeat violator cases $(27 \%)$.

The repeat violator rule, or death penalty as it's commonly known, was intended to punish institutions more severely. The Committee on Infractions has been granted the authority in these cases to impose additional penalties on the institution including: prohibiting some or all outside competition, eliminating all initial grant-in-aids and recruiting activities, requiring all institutional staff members to resign from their positions on select boards, forcing the institution to relinquish its voting privilege and generally enhanced major violation penalties (19.5.2.1.2). The only instance during this time frame of the Committee imposing a repeat violator penalty forcing the resignation of institutional staff members from their positions on boards came against the University of Texas El Paso in 1997. The UTEP case involved the improper receipt of financial aid by a nonqualifier, excessive grant-in-aids, ineligible competition, extra benefits and lack of institutional control against football, men's and women's basketball and rifle. The case had an aggregate score of violations of 39 with an aggregate score of penalties of just 5 with five years probation, vacation of record and a loss of scholarships. The football program lost 12 scholarships over two years while men's basketball and women's basketball each lost 4 total over 2 years. Along with these penalties the Committee decided to force the resignation of institutional staff members from NCAA boards.

Just two months later the Committee had another case before it involving a repeat violator. This time, the Committee refused to impose repeat violator penalties on Kansas State 
University. This case primarily involved recruiting violations and failure to monitor women's basketball camps. The aggregate score of violations was 15 with an aggregate score of violations equal to 5. Later that same month Grambling State was sanctioned for similar violations as Kansas State but was not categorized as a repeat violator. Grambling State received the same punishment.

The repeat violator status was shown to not have a significant effect on the overall level of sanctions imposed $(\mathrm{p}>.05)$. This means the severity of sanctions is not consistently enhanced by an institution's repeat violator classification. The failure of the Committee to sufficiently enforce enhanced penalties upon repeat violators diminishes the impact of NCAA rules and opens the door for further violations. By not imposing greater penalties on member institutions guilty of multiple major infractions within five years of each other, the Committee on Infractions is taking away its greatest weapon to deter future violations and creating an element of unfairness the next time it determines to use the repeat violator bylaw.

\section{Self-Imposed}

The severity of sanctions is influenced by self-imposed penalties (Table 4-6; $p<.05$ ).

Only 19 of the 262 major infraction cases analyzed did not involve the institution self-imposing some sort of penalty. Self-imposing penalties was first adopted by the University of Minnesota and has become common practice for offending institutions. Winfree \& McCluskey (2008) had previously determined that self-imposing penalties would be able to lessen the overall punishment imposed by the Committee on Infractions. This report furthers Winfree and McCluskey's findings in that it expands upon the knowledge that issuing your own penalties has the ability to affect the severity of overall sanctions. 
In the cases involving institutions that did not self-impose penalties, the data suggests less severe sanctions have been imposed than there would have been if the institution had issued even modest penalties. There have only been four cases of institutions not self-imposing even modest penalties since 2000. Most of those cases contained minimal violations with an average aggregate score of violations of 9.5 and an average aggregate score of sanctions at 1.5. Overall the aggregate score of violations for the $7 \%$ of cases not involving self-imposed penalties was 17.5 indicating a shift in institutional enforcement to realize the importance of imposing penalties especially when the violations are more severe. These institutions may not have felt it was necessary to assert their own penalty and instead allowed the NCAA to determine the severity of the sanction in hopes of avoiding being too punitive. This study suggests those institutions afraid of being too punitive are often times going to end up being punished harsher than an institution who issues the minimum level of self-imposed punishment. The NCAA views self-imposing penalties as an affirmation of guilt and acceptance of responsibility for the violations.

\section{Self-Reporting}

Self-reporting or self-discovering, in this study, includes the institution being notified of potential violations by an outside source so long as the institution was the one to first report the violation to the NCAA. In cases where a third party notified the NCAA first, the institution was not given credit for self-reporting even if they later filed a report without further inquiry from the NCAA.

A logistic regression model was run to determine the effect self-reporting would have on imposed sanctions. The model concluded that self-reporting violations does not significantly 
affect the severity of sanctions (Table 7-9; $\mathrm{p}<.05$ ). Self-reporting violations has become commonplace since the inception of language requiring each individual institution to monitor its own compliance with NCAA rules. Institutions are expected to provide optimal oversight of their athletic departments and to report known violations to the conference or NCAA offices. NCAA Bylaw 10.1 defines unethical conduct of student-athletes and institutional staff members. Included in the unethical conduct definition is the failure or refusal to provide complete and accurate information to the NCAA regarding possible violations.

A willful failure to report known violations would likely lead to a charge of lack of institutional control. Article 6 of the NCAA Constitution outlines the institutional control expected out of each of its members. NCAA Bylaw 6.01.1 places the control and responsibility for the conduct of the intercollegiate athletic department with the institution. Along with lack of institutional control, one of the most serious charges against an institution is failure to monitor. This charge often times surfaces when an institution lacks the necessary compliance oversight to prevent potential violations. The Committee has created additional expectations of programs regarding monitoring and enforcement. In 2010 the COI deemed it necessary for higher profile member institutions to provide greater oversight of its most recognizable student-athletes (University of Southern California, 2010). This type of dictum provides observable guidelines for institutions to adhere to. The case precedent now suggests it is mandatory for BCS schools to provide greater monitoring of its best football and basketball student-athletes and not doing so could result in a charge of failure to monitor. It would be reasonable to assume cases involving institutions that did not self-report would be more likely to face a failure to monitor charge. Not sufficiently monitoring and thereby discovering your own internal violations would naturally 
lead to failure to monitor charges. In fact, the same percentage (39\%) of institutions was charged with failure to monitor that did not self-report as those that did. Other factors may contribute to a failure to monitor violation but this study shows a clear indication that the COI does not consider self-reporting to be a mitigating factor.

While the size of athletic compliance staffs have continued to grow across the country with some institutions employing as many as 10 or more compliance officers, there are still numerous instances of major violations being discovered and reported by outside entities. George Dohrmann of Sports Illustrated has been credited with breaking several large rules violations while student run college newspapers, parents of student-athletes, boosters and opposing coaches have been known to inform the NCAA of potential violations long before the institution becomes aware of it. With greater awareness of the rules and closer monitoring by more employees, member institutions should be more apt at recognizing, discovering and reporting its own violations. Since 1994 , only $66 \%$ of major infractions were self-reported by the institution.

The fact that self-reporting has shown to have little to no significant effect on the severity of sanctions is somewhat disturbing. With the proscribed requirement under Articles 6 mandating institutional control and Article 10 outlining unethical conduct, the ability of an institution to self-report should be paramount to avoiding certain charges and limiting the severity of sanctions. Instead, the results imply self-reporting has no significant effect on the severity of sanctions. 


\section{IMPLICATIONS}

Research on NCAA sanctions creates a number of potential implications for professional insiders including NCAA management and university compliance officers. This research provides institutional compliance officers with a resource to help navigate the complex major rules infractions process. Providing an understanding of the significance each factor (selfimposed, self-reported, repeat violator, division) has on the severity of sanctions will help in the monitoring and enforcement phases of compliance oversight.

The NCAA recently created a working group on Enforcement charged with the task of recommending a new enforcement model and penalty structure (NCAA, 2012). This working group has proposed adopting four levels of violations instead of two (major and secondary). The sanctions have the ability to be reduced or increased from the proscribed standard set based on certain mitigating and aggravating factors. There would also be stricter sanctions imposed against violators including a reduction in scholarships up to $50 \%$ for a season and financial penalties as severe as 5\% of the institution's overall athletic budget. These recommendations are in the early phase of the legislative process and would not be expected to go into effect earlier than August 2013. In the coming months the NCAA will ask for member comments on the proposal. This is the opportunity for member institutions to voice their concerns over the legislative proposals before a vote is called for.

This research can serve as valuable information to those administrative staff members responsible for approving or denying legislative rule changes. In the very early stages of discussion surrounding the new penalty structure, there has been little negative feedback regarding its implementation. Much of the concern among institutions is that the public 
perceives the NCAA as arbitrary and capricious in its sanctioning thus creating a negative public perception against anyone that would fight against stricter and more standard penalties. The results of this research show that the NCAA has not been arbitrary in its sanctioning and the division of play has no significant effect on the severity of sanctions. This knowledge can only help administrative staffs to make more fully informed decisions regarding future legislative proposals. 


\section{LIMITATIONS}

As with any research there are certain limitations and delimitations. The research includes data only since the beginning of 1994 which precludes older decisions. The use of data began in 1994 at the time of rules mandating self-monitoring. This limits the data set to less than 20 years and ignores nearly four decades of previous cases. Including a larger set of cases will provide a deeper understanding of the changes the Committee on Infractions have adopted regarding sanctioning.

This study does not explore every potential mitigating or aggravating variable that would have an impact on the severity of sanctions. Though the COI has listed certain variables it considers being important factors in dispensing punishment, certain factors were not included based on suggestions from a panel of industry experts or due to the extreme difficulty deciphering the accuracy of each occurrence. Among the factors that were initially considered but later removed due to expert opinions were: the scope of violations, whether the violations were intentional, foreseeability of the violation and the level of cooperation with the investigation. The report ignores the cooperation of an institution (e.g., Arkansas, 2007; Illinois, 2005; Louisiana Lafayette, 2007) in the major infractions process as one of the mitigating variables suggested by the COI. This was not included as an independent variable due to the fact that the COI does not always allude to whether a member institution did or did not cooperate. Another variable not considered is the depth of the member institutions investigation (e.g., Arizona State, 2005; Arkansas, 2007). It would not have been possible to isolate every occasion that an institution conducted a thorough enough investigation to warrant mitigation. 
The reason for many of these factors being eliminated is that most of them are directly tied to further violations being charged which would inherently increase the ultimate punishment thereby effectively serve as being counted twice. If, for example, an institution was charged with recruiting violations stemming from excessive telephone calls to prospective student-athletes and the institution should have foreseen the possibility of those violations based on the coach's past actions, the institution would most likely have been hit with a failure to monitor charge as well as the recruiting violations. Thus the Committee has already taken the foreseeability into account when deciding whether to add further charges against the institution. An institution charged with the same number of impermissible telephone calls against a coach but with no reason to foresee the events would not be charged with a failure to monitor thereby having a lower aggregate score of sanctions. Similarly, considering the intentional nature of the violations was dismissed as a factor as intentional violations are going to lead to more severe charges than those deemed unintentional. The research is attempting to draw a line between factors that strictly influence the types and amount of violations being charged and the level of sanctions being imposed.

The type of sport(s) involved in committing the major rules violations did not lend itself to use in the logistic regression analysis. There are 37 NCAA sponsored sports with 31 sports being involved in a major infractions case since 1994 with revenue-generating sports (football, men's basketball and women's basketball) the most likely to be implicated. A significant portion of the data set (41\%) included multiple sports with as many as 16 sports (Alabama, 2009). Nearly $70 \%$ of the cases included one of the three traditional revenue-generating sports. By far the most egregious violator has been men's basketball having been a part of $46 \%$ of all major infractions since 1994. Football is second with 99 unique cases $(37.8 \%)$. The NCAA has 
addressed the complexities of football and basketball by creating substantially more oversight for those programs.

The enhanced rules structure for revenue-generating sports along with the complexity of analyzing each sport across the data set and isolating the impact caused by a specific sport made the analysis too burdensome. The severity of sanctions imposed on different sports has the potential to lead to charges of unfairness or bias. Fans of big-time college football often times feel sanctions against their programs are more severe than against Olympic sports while nonrevenue-generating sports bemoan the opposite. By not running the sport as an independent variable through the logistic regression analysis the study is hindered in its overall effectiveness to address the factors most likely to cause discrepancies in the sanctioning process.

The value attributed to each violation and sanction is open to debate. Other researchers may come up with different values, though NCAA rules and case precedent along with advice from industry experts were utilized to determine the value of each of these variables. Also, the NCAA has altered the importance it has placed on different violations. The COI, for instance, has stated the imposition of vacating records may be a more severe penalty due to its effect on past actions and potential for altering history books (Ferraro, 2003; Minnesota, 2002). The aggregate scores were not smoothed into different eras to potentially take into account the changing of emphasis placed upon each variable. Plus, it's possible the Committee feels sanctions are weighted differently depending on the level of competition. Television bans on FBS revenue-generating sports are certain to be more detrimental than bans on Division III Olympic sports. 
Another limitation may be that more punitive sanctions are levied against those institutions that self-imposed severe penalties. Institutions risk more severe punishment when they self-impose, than if they had allowed the COI to issue sanctions. This can be considered a limitation because the study does not intend to differentiate between the penalties imposed by the $\mathrm{COI}$ and those self-imposed. By not differentiating it is more difficult to predict exactly how the COI will act on future cases. By weighing the sanctions according to industry expert opinions and realizing the COI has allowed institutions to reduce self-imposed sanctions they deem too punitive (Florida A\&M, 2006; Arkansas-Fayetteville, 2007), the researcher is attempting to reduce the limitations.

The research is reliant upon the weighing of sanctions which may be debated by institutions, the NCAA and industry experts. This research intends to consider vacation of records and show cause as the least severe penalties based on the impact each has on the institution but the researcher is aware that others may feel these sanctions are more severe. The COI has stated the imposition of vacating records may be a more severe penalty due to its effect on past actions and potential for altering history books (Ferraro, 2003; Minnesota, 2002). In the same manner, a show cause sanction has a greater affect on the coach than it does on the university. This is a limitation because the opinions of industry experts might not precisely reflect the severity of the sanction in terms of its impact on programs subject to such penalty.

Finally, the study is limited by the exclusion of certain sanctions. Based on suggestions from industry experts, the researcher has decided to exclude a few potential sanctions. Among those sanctions not included are: public reprimand, financial penalties, and practice limitations. A public reprimand is included in every infractions case since 1994 making it virtually 
meaningless to the study. The research has not taken into account financial penalties imposed against institutions though this would seem like a logical step for future research. The imposition of financial penalties levied against major rule violators has just recently become an enhanced aspect of the sanctioning process. The researcher expected to find a drastic change in the issuance of financial penalties over the past 20 years of major infractions. This alteration in the sanctioning process may have a greater impact on the severity of sanctions than expected by the researcher and should be examined in any future research on the subject. The potential for financial penalties will become a topic of concern for the working group on enforcement as it provides a greater direct deterrent to the university. 


\section{FUTURE RESEARCH}

Previous research has explored the trends associated with major infractions but have done so without insight into the mitigating and aggravating factors effecting overall sanctions. Further research regarding NCAA penalties should investigate the relevance of other mitigating and aggravating variables. Researchers should analyze the impact of institutional cooperation as well as significant corrective actions (improved compliance procedures) on the severity of sanctions. The Committee on Infractions appears to be imposing greater financial penalties on violators. This variable should be considered in future research. Future researchers may want to examine further types of sanctions such as financial penalties and practice limitations.

Future research should explore in greater depth the severity of sanctions on each sport. A logistic regression analysis could be run predicting sanctions based on every individual sport program. This would require a breakdown of each case to determine which violation and sanction is attributed to which sport. Due to the challenge of isolating this information according to each sport, a smaller sample size could be utilized for this purpose. Future research could also examine the difference between the severity of sanctions assessed to men's programs compared to the women's programs. This line of research would fit with previous gender equity based studies and could expand on the various Title IX initiatives.

A qualitative study could be conducted exploring the reasoning behind institutions deciding whether to self-report. No substantial research has been conducted regarding institutional self-reporting or self-discovering. It would be beneficial to understand the reasons behind an institution not being aware enough to discover and report its own violations. With journalists attempting to scoop large scandals there is a growing awareness of major infractions 
occurring on campuses across the country. Figuring out the reasons why institutions are unaware of ongoing violations may help to strengthen the compliance department. An examination of this area could also focus on the level of rules education being distributed by compliance departments and the level of monitoring.

An analysis could be done on the types of monitoring programs being put into place. More institutions are leaning on professional database services (ACS, JumpForward) to maintain records and monitor bylaw compliance. Companies have also been created solely for the purpose of keeping track of student-athletes use of social media (e.g., U-Diligence). A simple quantitative or qualitative study could be conducted discussing the background of compliance department personnel. As more jobs are being added to the field, a comprehension of the qualifications of those who enforce the rules could shine more light on the future of NCAA enforcement. 


\section{CONCLUSION}

In summary, this study provides athletic administrators and NCAA personnel information regarding the severity of sanctions imposed on institutions that have committed major rules infractions. It contains crucial data indicating the fairness of the Committee on Infractions' decisions thereby providing for improved relations between the NCAA and its member institutions. The NCAA working group on enforcement may be able to utilize some of the findings found in this report to create a new model for enforcement and penalty structure. The results of this study will also provide greater clarity to the general public in explaining the decisions made by the Committee.

This research also confirms the findings of Winfree \& McCluskey (2008) that selfimposing penalties can affect the severity of sanctions issued by the Committee on Infractions. A logistic regression test concluded that the severity of sanctions is influenced by the selfimposed penalties $(\mathrm{P}<.05)$. Very few institutions charged with major violations fail to selfimpose some minimum amount of penalties and the findings would indicate it is a good idea for institutions appearing before the COI to continue self-imposing in order to avoid greater punishment.

A wide speculation among the general public regarding NCAA major infraction cases is that the division (size of athletic program) or level of competition impacts the severity of sanctions imposed. The old adage, the smaller schools are punished for the sins of the larger and more prestigious member institutions, suggest a belief that decisions are unfair or biased against certain programs. The findings of this study indicate the severity of sanctions imposed by the 
COI is not influenced by the division or level of competition. This discovery could help provide greater confidence in the NCAA sanctioning process.

Perhaps the most compelling finding of the study is that the repeat violator status may not significantly affect the severity of sanctions $(\mathrm{p}>.05)$. The repeat violator bylaw grants the COI the authority to impose significantly harsher penalties on an institution guilty of committing its second major infraction within five years of a previous major case. While the COI has the power to subject the institution to enhanced major violation penalties, including the death penalty, rarely have they utilized that power. Of the 41 repeat violator cases in the data set, only 15 have been penalized with at least a one year postseason ban and only twice has the institution been given a television ban (Mississippi, 1994; Texas A\&M, 1994). The COI is not as likely to impose greater sanctions on repeat violators as they may have been nearly two decades ago. A typical negative reaction for opponents of the NCAA and $\mathrm{COI}$ is that there decision making is arbitrary. This finding should be a concern for the NCAA as it potentially demonstrates an area of arbitrary decision-making. The COI has the power and is expected to use that power to severely punish repeat violators with greater sanctions but for some reason has not consistently done so. This makes the organization appear unfair and biased, as most of the repeat violators are major FBS institutions and involved revenue generating sport programs. Over $80 \%$ of repeat violators are from Division I FBS with 61\% (25 of 41) from the top BCS level. There has yet to be a repeat violator from either Division II or III.

The final variable considered by the study examined the effect self-reporting or selfdiscovering violations has on the severity of sanctions. The logistic regression analysis showed that the self-reporting variable is not significantly affected by the severity of sanctions ( $\mathrm{p}>.05)$. 
Therefore, self-reporting violations does not help mitigate the sanctions imposed. Though athletic programs are employing more compliance officers than ever before and many of them possessing a law degree, violations still go undetected by the institution. When a third party alerts the NCAA to potential violations it could lead to charges of failure to monitor. 


\section{BIBLIOGRAPHY}

Barnes, J. C., \& Marley, S.C. (2009). An analysis of Division I-A compliance officers' perceptions of NCAA freshman eligibility requirements. International Journal of Sport Management, 10 (3), 330-349.

Baxter, V., Margavio, A.V., \& Lambert, C. (1996). Competition, legitimation, and the regulation of intercollegiate athletics. Sociology of Sport Journal, 13, 51-64.

Blumenthal, R. (2012, April 18). Blumenthal calls on NCAA to amend new academic standards, increase fairness for student-athletes. Available from http://blumenthal.senate.gov/newsroom/press/release/blumenthal-calls-on-ncaa-toamend-new-academic-standards-increase-fairness-for-student-athletes

Carter, A. (2012, March 12). NCAA hits UNC football hard for violations. The Charlotte Observer. Retrieved from http://www.charlotteobserver.com/2012/03/12/3093085/uncsthorp-ncaa-penalties-painful.html

Clark, R., \& Batista, P. J. (2009). Do BCS National Championships lead to recruiting violations? A trend analysis of NCAA Division I (FBS) infractions. Journal of Sport Administration \& Supervision, 1, 8-22.

Clifton, T.J. (2009). Does the crime justify the punishment? An in-depth look at the Indiana University phone call scandal. DePaul Journal of Sports Law and Contemporary Problems, 6, 73 .

Depken II, C.A., \& Wilson, D.P. (2006). NCAA enforcement and competitive balance in college football. Southern Economic Journal, 72, 826-845.

Dixon, M., Turner, B.A., Pastore, D.L, \& Mahony, D. (2003). Rule violations in intercollegiate athletics: A qualitative investigation utilizing an organizational justice framework. Journal of Academic Ethics, 1, 59 - 90.

Eckard, E.W. (1998). The NCAA cartel and competitive balance in college football. Review of Industrial Organization, 13, 347-369.

Falla, J. (1981). NCAA: The voice of college sports. Mission, KS: National Collegiate Athletic Association.

Ferraro, F. (2003). When athletics engulfs academics: violations committed by University of Minnesota basketball. DePaul Journal of Sports Law and Contemporary Problems, 1, 13. 
Fleisher, A., Goff, B.L., Shughart, W.L., \& Tollison, R.D. (1988). Crime or punishment? Enforcement of the NCAA football cartel. Journal of Economic Behavior \& Organization, 10(4), 433-451.

Fleisher, A., Goff, B.L., \& Tollison, R.D. (1992). The National Collegiate Athletic Association: A Study in Cartel Behavior. Chicago, IL. University of Chicago Press

Fort, R. \& Quirk, J. (1999). The College Football Industry. Sports Economics, 11-25.

Grimes, P.W., \& Chressanthis, G.A. (1994). Alumni contributions to academics: the role of intercollegiate sports and NCAA sanctions. American Journal of Economics and Sociology, 53, 27-40.

Humphreys, B.R. \& Ruseski, J.E. (2006). Financing Intercollegiate Athletics: The Role of Monitoring and Enforcing NCAA Recruiting Regulations. International Journal of Sport Finance, 1(3), 151-161.

Jordan, J. S., Greenwell, T. C. Geist, A. L. Pastore, D. L. \& Mahony, D. F. (2004). Coaches' perceptions of conference code of ethics. The Physical Educator, 61(3), 131-145.

Knight Foundation-Commission Intercollegiate Athletics (2001). A call to action: Reconnecting college sports and higher education. Charlotte, NC.

Legislative Services Database for the Internet by the National Collegiate Athletic Association (2011). Major infractions search. Retrieved on June 9, 2011 from, https://web1..ncaa.org/LSDBi/exec/miSearch

Legislative Services Database for the Internet by the National Collegiate Athletic Association (2011). Secondary violations self-reporting: recent news. Retrieved on June 9, 2011 from, http://ncaa.org/wps/myportal/ follow secondary infractions link under enforcement/AGA section.

Mahony, D. F. (1999). Collective reaction to injustice in intercollegiate sport: Injustice to women and student athletes as test cases. Journal of Sport \& Social Issues, 23, 328-352.

Mahony, D.F., Fink, J., \& Pastore, D. (1999). Ethics in intercollegiate athletics: an examination of NCAA violations and penalties. Professional Ethics, 7 (2), 53-74.

Marsh, G.A. (2009). A call for dissent and further independence in the NCAA infractions process. Cardoza Arts \& Entertainment Law Journal, 26, 695.

National Collegiate Athletic Association Manual (2011). Indianapolis, IN. 
NCAA (2012, January 13). NCAA recommends violation structure. NCAA.com. Retrieved from http://www.ncaa.com/news/ncaa/article/2012-01-13/ncaa-recommends-violationstructure

Perry, M.E. (2002). An analysis of NCAA major violation penalties and on-the-field success. Microform Publications, University of Oregon.

Sack, A.L. (1988). Are improper benefits really improper? A study of college athletes' views concerning amateurism. Journal of Sport \& Social Issues, 12, 1-16.

Smith, E. (2012, April 27). NCAA takes away scholarships from South Carolina football. USA Today. Retrieved from http://content.usatoday.com/communities/campusrivalry/post/2012/04/south-carolinafootball-scholarship-reductions-ncaa-violations/1

Smith, R. K. (2000). A brief history of the National Collegiate Athletic Association's role in regulating intercollegiate athletics. Marquette Sports Law Review, 11(1), 9-22.

Staples, A. (2012, March 12). UNC case shows how reward still outweighs risk for cheating. Sports Illustrated. Retrieved from http://sportsillustrated.cnn.com/2012/writers/andy_staples/03/12/north.carolina.sanctions/ index.html

Thamel, P. (2011, August 16). Hurricane players and recruits accused of NCAA violations. The New York Times. Retrieved from http://www.nytimes.com/2011/08/17/sports/ncaafootball/miami-hurricanes-accused-ofncaa-violations.html

Weston, M.A. (2011). Symposium issue: The NCAA at 100: perspectives on its past, present, and future: Article: NCAA sanctions: assigning blame where it belongs. Boston College Law Review, 52, 551.

Wieberg, S. (2008, October 30). NCAA looking to send message with sanctions. USA Today, pp. $11 \mathrm{C}$.

Winfree, J.A., \& McCluskey, J.J. (2008). Incentives for post-apprehension self-punishment: University self-sanctions for NCAA infractions. International Journal of Sport Finance, 3 (4), 196-209.

Zimbalist, A.S. (1999). Unpaid professionals: Commercialism and conflict in big-time college sports. Princeton, N.J. Princeton University Press. 